CZU 342.7

DOI: https://doi.org/10.52388/2345-1971.2021.1.04

\title{
INTERACTION OF CONSTITUTIONAL GUARANTEES OF HUMAN RIGHTS WITH POWER, ECONOMY AND CAPITAL
}

\author{
Alexandr TERNOVSCHI \\ $\mathrm{PhD}$ student, University of European Political and Economic Studies „Constantin Stere”, \\ Chisinau, Republic of Moldova \\ e-mail:alex-ternovsky@yandex.ru \\ https://orcid.org/0000-0002-0636-4628
}

The article contains a study in the field of interaction and dependence of constitutional guarantees of human rights in the Republic of Moldova on power, economy and capital. An example is given of the set of meanings and forms of this democracy, the measure, level and values of the citizens who make up a collective or make up the crowd, from the point of view of organizing the means by leading the people over the state. The causal relationship is analyzed between the interaction and the direct dependence of the implementation of the constitutional norms on the political will, the level of the economy, including the interest and purpose of the capital dictatorship. This prism studies the real issue of democracy in the Western sample regarding the completeness of citizens' expectations. The article provides an assessment of democratic values in their presence, ie form. The most frequent and richest opinions, ideas and doctrines are evaluated, for the general ideological purpose, in order to effectively achieve objectives, including the subsequent onset of certain consequences. A comparative analysis is made regarding the opinions of other authoritarian specialists in this field.

Keywords: democracy, Constitution, human rights, power, economy, capital, state of law.

\section{INTERACTุIUNEA GARANȚIILOR CONSTITUȚIONALE A DREPTURILOR OMULUI CU PUTEREA, ECONOMIA ȘI CAPITALUL}

Prezentul articol conține un studiu în domeniul interacțiunii și dependențeigaranțiilor constituționale ale drepturilor omului în Republica Moldova de putere, economie și capital. Autorul analizează setul de sensuri și forme ale acestei democrații, măsura, nivelul și valorile cetățenilor care alcătuiesc un colectiv sau o mulțime de persoane, din punctul de vedere a mijloacelor și metodelor de aplicare a principiilor democratice prin prisma implicării cetățenilor în conducerea statului. Relația cauzală este analizată între interacțiunea şi dependența directă a punerii în aplicare a normelor constituționale prin voința politică, nivelul economiei, luând în considerație interesul și scopul capitalului. Este pusă in discuție și problema reală a democrației de tip occidental cu privire la așteptările cetățenilor. Articolul oferă și o evaluare a valorilor democratice în actuala lor formă și conținut. Sunt analizate cele mai frecvente și independente opinii, idei și doctrine. La fel, se efectuează un studiu din punctul de vedere general ideologic și obținerea unor efecte obiective, inclusiv apariția ulterioară a anumitor consecințe. Se face, la fel, și o analiză comparativă cu privire la opiniile altor renumiți specialiști în acest domeniu.

Cuvinte-cheie: democrație, Constituție, drepturile omului, putere, economie, capital, stat de drept.

\section{INTERACTION DES GARANTIES CONSTITUTIONNELLES DES DROITS DE L'HOMME AVEC LE POUVOIR, L'ÉCONOMIE ET LE CAPITAL}

Cet article contient une étude dans le domaine de l'interaction et de la dépendance des garanties constitutionnelles des droits de l'Homme en République de Moldova vis-à-vis du pouvoir, de l'économie et du capital. L'auteur analyse l'ensemble des significations et des formes de cette démocratie, la mesure, le niveau et les valeurs des citoyens qui composent un collectif ou beaucoup de personnes, du point 
de vue des moyens et des méthodes d'application des principes démocratiques à travers le prisme de l'implication des citoyens dans la direction de l'État. La relation causale est analysée entre l'interaction et la dépendance directe de la mise en њuvre des normes constitutionnelles par la volonté politique, le niveau de l'économie, en tenant compte de l'intérêt et du but du capital. Le véritable problème de la démocratie de type occidental en ce qui concerne les attentes des citoyens est également analysé. L'article fournit également une évaluation des valeurs démocratiques dans leur forme et leur contenu actuels. Les opinions, idées et doctrines les plus courantes et les plus indépendantes sont analysées. De même, une analyse est effectuée du point de vue idéologique général et de la réalisation d'effets objectifs, y compris l'apparition ultérieure de certaines conséquences. Une analyse comparative est faite sur les opinions d'autres spécialistes célèbres dans ce domaine.

Mots-clés: démocratie, Constitution, droits de l'homme, pouvoir, économie, capital, état de droit.

\section{ВЗАИМОДЕЙСТВИЕ КОНСТИТУЦИОННЫХ ГАРАНТИЙ ПРАВ ЧЕЛОВЕКА С ВЛАСТЬЮ, ЭКОНОМИКОЙ И КАПИТАЛОМ}

Статья содержит исследование в области взаимодействия и зависимости конституционных гарантий прав человека в Республике Молдова от власти, экономики и капитала. Приводится пример множественности смыслов и форм этой демократии, меры, уровня и иенностей граждан, составляющих коллектив, либо образующих толnу, относительно организащии способов её применения, при народном управлении государством. Анализируется причинная связь между взаимодействием и прямой зависимостью исполнения конституционных норм от политической воли, уровня экономики, включая интерес и цель диктатуры капитала. В этой связи, изучена актуальная проблема демократии западного образиа относительно полноты ожиданий граждан. В статье приводится оценка демократических иенностей в их настоящем виде, смысле и форме. Оиениваются наиболее распространенные и состоятельные мнения, идеи и доктрины - от их идеологического общего предназначения до фактически достигаемых иелей, включая последующее наступление определенных последствий. Осуществлен, также, сравнительныгй анализ относительно мнения других авторитетных спеииалистов в этой области.

Ключевые слова: демократия, Конституция, права человека, власть, экономика, капитал, правовое государство.

\section{Введение}

Статья содержит исследование в области взаимодействия и зависимости конституционных гарантий прав человека в РМ от власти, экономики и капитала. Анализируется причинная связь между взаимодействием и прямой зависимостью исполнения конституционных норм от политической воли, экономики и капитала. Сквозь эту призму изучается актуальная проблема демократии западного образца относительно полноты ожиданий граждан. В статье приводится оценка демократических ценностей в их настоящем виде, смысле и форме. Проделывается сравнительный анализ относительно мнения других специалистов в этой области. Анализируются все имеющие место быть существенные аспекты, идеи и цели, исходящие из реаль- ных теоретически-демократических призм, исследуется их путь и окончательный эффект действий, включая разницу между ожиданием от первоначальной идеи до получаемого результата, включая скрытый смысл демократического проекта целиком. Проделывается сравнительный анализ в совокупности с мнением других специалистов в этой области.

Актуальность данного исследования обусловлена тем, что в настоящее время большинство государств стремятся к созданию демократическо-правового государства, где главной ценностью являются права человека и народовластие через делегированных делегатов. Важность изучения данной области исходит от прямой зависимости этих конституционных гарантий от проявления политической воли, соразмер- 
но интересу капитала и уровню экономики государства.

Цель исследования - установить и исследовать причинную связь между конституционными гарантиями прав человека относительно проявления политической воли, исходя из возможностей экономики государства и предпочтения капитала.

Методологическая основа работы состоит из общеизвестных принципов, вытекающих из поставленной задачи, куда включаются диалектический метод и историзм, изучение и анализ правоприменительной практики, и другие.

Структура работы обусловлена ее целями и задачами. Она состоит из научного исследования фактов, их анализа, выводов и библиографического списка.

\section{Западная демократия, права человека и гарантии Конституции Республики Молдова}

В статье проводится исследование в области реализации ценностей западной демократии, прав и свобод человека, гарантированных Конституцией Республики Молдова, её взаимодействию и зависимостью от политической воли, уровня экономики государства и капитала.

В Преамбуле Конституции Республики Молдова она провозглашена главным законом государства. В первом разделе Конституции «Основные принципы» декларируется положение, что «Республика Молдова - демократическое правовое государство, в котором достоинство человека, его права и свободы, свободное развитие человеческой личности, справедливость и политический плюрализм являются высшими ценностями и гарантируются» [1]. Данное положение является фундаментальной основой конституционного строя РМ.

Первое представление о демократии как формы правления возникло в античной Греции. Древнегреческие философы утверждали, что все люди равны от рождения и имеют одинаковые, дарованные природой права [2]. Граждане древней Греции считали самой главной свободу человека и его неотчуждаемые права, принадлежащие ему от рождения. Эту свободу гарантировала частная собственность на имущество, в том числе на землю. Поэтому в Греции развился свободный рынок, который обеспечивал ее жителям более высокий уровень жизни, чем у соседних народов. Демократические традиции собрания граждан, позволяли проявлять инициативу их большому количеству, что придавало им ощущение свободы, возможности непосредственно влиять на внутреннюю и внешнюю политику, на все важные вопросы своего города-государства, как жизни народа, так и его взаимоотношений с соседями. В этом античном обществе гражданскими правами пользовались немногие, равенство прав и обязанностей признавалось только внутри сообщества граждан. Велика была степень контроля общества над частной жизнью индивида. Территория города-государства не должна была расширяться, иначе невозможным стало бы личное участие каждого гражданина в народном собрании. Соответственно число полноправных граждан не должно увеличиваться свыше определенного предела. В изложенном смысле удержан определенный демократический ценз, который гарантировал преимущественно качество над количеством.

Основополагающие принципы западной демократии сочли неприемлемыми демократический ценз института «Афинской» демократии, в условиях появления государственных образований и представили иную модель демократической ценности, в которой права человека признаются за каждым гражданином, что все граждане и в любом количестве обладают правом принятия участия в народном собрании и определения судьбы, как внутри своего государства, так 
и во внешней его политике. При этом, несмотря на знаменитую формулу софиста Протагора о том, что «Мера всех вещей человек» [3], смысл западной демократии исключил какие бы то ни было цензы и гарантировал доминирование количества над качеством, в области общественного контроля народного собрания по определению внутренней судьбы государства, и его внешней политике.

Сегодня демократическим признаком правового государства является реальное обеспечение прав и свобод личности. Уровень выполнения конституционных гарантий прав и свобод человека отождествляется с его зрелостью и соответствием правовому государству. Важно отметить, что на практике, главенствующее право в признании какого-либо государства правовым и демократичным, по умолчанию, делегируется США и их отдельным европейским сателлитам, составляющим ось цивилизованного мира. Именно США, неоспоримо считается прародителем западной модели демократии и доминирует в её экспорте по всему миру. В этом смысле, успешно экспортируется популярная формула успеха, что лучшей гарантией прав человека может быть закон, который призван охранять важнейшие интересы личности, облеченные в форму права. Однако, считается, что истинно демократическое правовое государство наделяет своих граждан, как правами и свободами, но так и налагает на них определенные обязанности. Весьма важно, чтобы права и свободы граждан были соответствующим образом гарантированы, в противном случае они из блага превращаются в пустые лозунги, не представляющие никакой ценности. В идеале правового государства граждане ожидают принцип господства взаимной ответственности между государством и личностью. Определяя в законах меру свободы личности, государство в этих же пределах огра- ничивает себя в собственных решениях и действиях, и соответственно наоборот, правомерные решения и действия государственных органов в определенных случаях могут ограничивать свободу личности. Таким образом, институт прав и свобод личности является фундаментальным в области Конституционного права правового государства.

Однако, анализ теории и практики применения западной модели демократических ценностей, позволяет наглядно продемонстрировать несоответствующее соотношение продиктованных теорией, от фактического положения превозносимых принципов западного цивилизованного мира, которые должны иметь место в современной жизни у каждого гражданина, но дефакто оказываются доступными лишь для малой их части. Именно в этом смысле западный принцип демократии неоспоримо показывает преобладание количества над качеством и легко передает власть толпе, которую быстро подменяет деньгами. Это напоминает известный афоризм: «Толпа преступна и бессмысленна, она кричала: «Распни Его (Христа)!», в которого и уверовала». Поэтому свободной должна быть не одемокраченная толпа, а качественный коллектив, способный организовать работу над поставленной задачей.

Практика показывает, что на протяжении тридцати лет независимости Республики Молдова импортированный вариант западной демократии стремительно передал власть народу через парламентаризм, который в свою очередь не реализовал заветную мечту, а породил глобальную смуту, которую использует для искажения реальности в глазах народа, чтобы пользоваться полнотой этой власти и административным комфортом, преследуя цель достигнуть абсолютную власть, в борьбе за которую, смело применяет интриги и политические перевороты. 
В частности, удачным примером служат в определенной части неисполняемые конституционные гарантии Республики Молдова, что подтверждается различными ежегодными докладами о соблюдении прав человека в Республике Молдова, как ОБСЕ, Госдепартаментом США, так и рядом других аккредитованных международных и европейских организаций. При этом, напрашивается справедливый вопрос о целесообразности и благонамеренности требований цивилизованного мира по юридическому приведению конституционных гарантий прав и свобод человека, в частности, Республики Молдова, в соответствие с международными европейскими нормами, но при отсутствии на то реальных возможностей и соответствующего потенциала у государства.

В этом спектре, напрашивается пример прямого доступа к пользованию западными демократическими ценностями теми гражданами, которые обладают капиталом и наоборот. На практике, каждый шаг от самого рождения - покупки пеленок, распашонок, и до панихиды (погребальной церемонии), современного гражданина, связан с капиталом. Таким образом, доступ к просвещению и получению специального высшего образования за счет государства зависит от способностей индивида, то есть платный для большинства, к медицинскому обслуживанию - после покупки полиса, к правосудию - через оплату услуг адвоката. То есть, перечисленные блага, доступны обладателям капитала, а равно от его количества зависит их уровень качества. При отсутствии финансовой способности гражданина, государство не оказывает помощь в покупке медицинского полиса, оплате адвокатских услуг в области гражданского права, а в уголовном судопроизводстве практика показывает на отсутствие гарантий качества предоставляемой государством юридической помощи, но в это же самое время, госу- дарство прямо гарантирует гражданину достойную жизнь, в том числе пищу, одежду, жилище, медицинский уход и необходимое социальное обслуживание. Как парадокс, но подавляющее большинство граждан, получает пенсии и пособия по инвалидности существенно ниже прожиточного минимума, определенного самим государством. То есть, превозносимые западные демократические ценности достойной жизни, прав и свобод человека, красуются аппетитными деликатесами на привлекательной, но недоступной витрине для большей части граждан. Таким образом, изложенный смысл состоятельно аргументирует существо волшебности основания роста популярности западной демократии у граждан, который внешне легко предоставляет власть народу, но быстро подменяет её деньгами.

Еще со знаменательной даты по обретению Республикой Молдова независимости, когда была провозглашена Декларация Независимости Республики Молдова, в которой утверждены ценности о вековом стремлении народа жить в суверенной стране, провозглашении её независимости, признавая правовое государство, гражданский мир, демократию, достоинство человека, его права и свободы, развитие человеческой личности, справедливость и политический плюрализм высшими ценностями, сознавая свою ответственность и долг перед прошлыми, нынешними и будущими поколениями, подтверждая приверженность общечеловеческим ценностям..., казалось, что наступил долгожданный момент, когда уставший народ может подняться и гордо расправить усталую грудь, вдохнуть свежий воздух обнадеживающих перемен и реализовать обретённое право на лучшую жизнь, избранием своих народных делегатов на свободных и демократических выборах при тайном голосовании, в условиях выполнения гарантий свободы выражения мнения, что вошло в основу смысла современного 
демократического и правового государства. Впервые воля народа избирать своих народных представителей в публичные органы власти и управлять государством, была гарантирована принятой Конституцией Республики Молдова от 27.08.1994 года. Это послужило обретением Парламента статуса высшего представительного органа народа Республики Молдова и единственной законодательной властью государства. Граждане республики стали жить предвкушением скорейшего наступления изобилия и благополучия по западному образцу.

Несмотря на перечисленные успехи и конституционные гарантии, осталась одна из наиболее важных, малоизученных и актуальных проблем Республики Молдова, - это иррациональный результат от принятой западной демократической формы народовластия, что подтверждается показателями по отсутствию развития республики и удручающим жизненным уровнем граждан, несмотря на возложенные надежды от полученных свободы слова, демократии, выборов народных делегатов, учитывая их высокий и профессиональный организационный уровень, включая грамотно отлаженный механизм их проведения. Все рациональные расчеты и попытки вывести соответствующим путем республику из кризиса потерпели фиаско, что повлекло разочарование и стремительное сокращение доверия народа к своим представителям в органах власти. И, соответственно, снизило активность участия граждан на электоральных процессах. Основная причина проблемы в изложенном смысле сводится к тому, что де-факто, делегированные народом представители в публичные органы власти, являются выдвиженцами капитала, редко обладают специальными знаниями и опытом в области управления государством, применяют активные действия по снисканию электоральных симпатий у граждан, и поэтому живут в большей части в жестком календаре выборов, чем под контролем самого общества и закона. Справедливо отметить неэффективные реформы высшего законодательного органа, особенно в области приватизации, которые судьбоносно отразились на экономике и как следствие безнадежных перспективах Республики Молдова.

Посредством приватизации, государственное имущество (производства, заводы, фабрики и т.п.) было передано в «частные руки» трудящегося народа, что предсказуемо привело к их быстрому банкротству и последующей перепродаже, по искусственно заниженной цене, синдикату. В итоге, государство осталось без промышленности, без производства и без денег, а народ лишился рабочих мест и возможности содержать семьи.

В этом смысле справедливо вспомнить как классики охарактеризовали, актуальную и сегодня, практику парламентаризма: «Главное занятие депутатов - это бесконечные разглагольствования и выманивание взяток» [4]. Аналогичного мнения придерживался и Победоносцев К.П. который высказал мысль о том, что «Парламентаризм - это величайший обман нашего времени, порождающий продажность СМИ, политических партий, чиновников и фальшь буржуазных выборов» [5]. Довольно близко с ними и пророчески мудро о западных правах человека, высказался Ленин В.И.: «Право - это воля господствующего класса, возведенная в закон». То есть, интерпретируя данную формулу согласно современным реалиям и юридической форме, получается следующее: «Властвующий синдикат обладателей капитала, формирует законодательные органы своими выдвиженцами, которые принимают нужные законы, формирующие правовую систему, полностью отрицающую волю и интересы народа, но всецело защищающую и обслуживающую интересы этого синдиката». Этим объясня- 
ется наступивший в республике правовой кризис, при котором для защиты нарушенного права рядового гражданина, указанный обращается в суд, но там действует воля властвующего синдиката возведенная в закон, в лимиты которого не вписывается интерес и долг по защите природных прав и свобод человека, положенных ему от рождения, равно как и не вписывается выполнение прописанных прав гарантируемых Конституцией, национальными законами и международными соглашениями.

Изложенная мысль исчерпывающе была растолкована Йозефом Геббельсом, заметивший что «Юриспруденция - продажная девка в политике» [6].

Наш современник Б. Березовский выразился еще предметнее: «Капитал нанимает на работу власть. Форма найма называется «выборы». Мне эта фраза показалась познавательной, поскольку мы все еще бываем наивными на выборах» и «Политики - это наёмные рабочие предпринимателей» [7].

По объективной причине, в последние годы тема избрания гражданами своих представителей в органы власти и, соответственно, изобретение методов народного контроля над ними принимает всё большую актуальность, растет интерес и важность для исследования этого механизма более детальным и глубоким методом. Причина тому, это не наступление ожидаемых гражданами положительных перемен. На протяжении последних трех десятилетий видится экономический, социальный, научный и культурный регресс, с каждым годом увеличивается проблематика обесправливания граждан республики, их манипулирование и использование лукавством, со стороны малочисленной группы синдиката, входящей в тандем с народными делегатами, на которых возлагались искренние надежды перемен, путем избрания на открытых, демократических и свободных выборах западного образца.
Данная проблема, главным образом, происходит в силу того, что фундамент западной демократии основан на капитализме. При этом, интересы капитала гарантированы ст. 126 Конституции РМ [1], которая предусматривает, что экономика Республики Молдова является рыночной, социально ориентированной, основанной на частной и публичной собственности и свободной конкуренции. Что государство должно обеспечивать свободу торговли и предпринимательской деятельности, защиту добросовестной конкуренции, создание благоприятных условий для использования всех производственных факторов. Иными словами, государство Основным законом гарантирует критерий для принятия экономических решений по стремлению к увеличению капитала и к получению прибыли, что в целом составляет капитализм.

Принимая во внимание, что экономика Республики Молдова является рыночной и законодательно гарантирует стремление государства к увеличению капитала и получению прибыли, то соответственно напрашивается разумный вывод, что это капиталистическая система экономики. Как известно, основным правилом и даже законом капиталистической экономики является рост капитала - увеличение прибыли. Английский публицист XIX века T. Дж. Даннинг писал: «Капитал ... избегает шума и брани и отличается боязливой натурой. Это правда, но это ещё не вся правда. Капитал боится отсутствия прибыли или слишком маленькой прибыли, как природа боится пустоты. Но раз имеется в наличии достаточная прибыль, капитал становится смелым. Обеспечьте 10 процентов и капитал согласен на всякое применение, при 20 процентах он становится оживлённым, при 50 процентах положительно готов сломать себе голову, при 100 процентах он попирает все человеческие законы, при 300 процентах нет такого преступления, на которое 
он не рискнул бы, хотя бы под страхом виселицы. Если шум и брань приносят прибыль, капитал станет способствовать тому и другому. Доказательство: контрабанда и торговля рабами» [8].

Исходя из этого, справедливо ставится под сомнение искренняя добросовестность борьбы за права и свободы человека в демократическом государстве при капиталистической экономике, учитывая, что за место получения ожидаемой прибыли, эта область требует регулярных и существенных инвестиций, а значит не окупаемых растрат. Естественно, что возможность качественно соблюдать права и свободы человека, в существенной части зависит от уровня и стабильности экономики государства. Другое дело, когда экономической возможности просто нет и государство предсказуемо обречено без внешней материальной помощи, а старшие партнеры - оси цивилизованного мира, осознано настаивают на принятии изначально невыполнимых, но декларативно гуманных законов, и международных соглашений в области защиты прав человека, которые не способствуют увеличению капитала. С большой долей вероятности напрашивается разумный вывод, что для определенного и эффективного корректирования политических действий власти, а также оказания влияния на управление некоторыми внутренними процессами суверенного государства, «старшие» наставники по демократии, в лице внешних партнеров, своевременно манипулируют национальными упущениями в этой области, констатируют их в своих годовых отчетах, санкционируют через международный институт ЕСПЧ и этим профессионально манипулируют, как сменой общественного мнения, так и массовым отношением народа к этой национальной власти - находящейся под электоральной зависимостью избирателей, побуждая эту «народную» власть таким образом проявить политическую волю в нужном для них направлении. В настоящее время, опосредованный механизм принятия решений в Республике Молдова во многом зависит от экспертизы ПАСЕ, Венецианской комиссии, разрешения МВФ, согласования со Всемирным Банком, одобрения НПО, существующих на западные гранты. К примеру, в начале февраля 2016 премьер-министр Молдовы Павел Филип честно признался: «Проект бюджета уже разработан, обсужден с предпринимателями, профсоюзами и патронатами. Его черновик уже передали депутатам. Должно пройти последнее обсуждение с МВФ» [9].

Справедливо заметить, что в определенной мере политическая воля власти государства, для самосохранения занимаемого административного положения, вынуждена выполнять минимальные нормы прав человека в области социальных гарантий по выплате пенсий и заработных плат бюджетникам, иначе начнется государственный хаос, при котором эта власть врятли удержится. Чтобы стабилизировать свою власть в этом смысле, народным делегатам пришлось ввести республику в сателлит кандидата в члены государств из семьи цивилизованного мира, что гарантировало регулярную финансовую помощь, оказывающую решающее значение по выполнению минимальных норм для поддержания жизнеспособности государства. Таким образом, благодаря проявленной политической воле, на национальном уровне были закреплены международные нормы и стандарты по правам человека в законодательстве Республики Молдова. В этот период было провозглашено равенство всех людей, их право на жизнь, свободу и благополучие. Государственная властьгарантировала всем гражданам республики, иностранным гражданам и лицам без гражданства, права и свободы, предусмотренные Конституцией, ЕКПЧ, включая и другие законодательные акты, общепризнанные принципы и нормы меж- 
дународного права. Были гарантированы равные возможности и права для осуществления своей деятельности политическим партиям, общественно-политическим организациям и движениям, гражданам и национальным, этническим и языковым группам, действующим в рамках Конституции, были гарантированы социальные, политические, экономические, культурные права и свободы. В подтверждение приверженности общепризнанным принципам и нормам международного права, стремлению к соблюдению прав человека, Парламент Республики Молдова проявил политическую волю и Постановлением от 28.07.1990 принял решение о присоединении Республики Молдова к Всеобщей Декларации прав человека от 10.12.1948, а также принял Постановление о присоединении Республики Молдова к международным правовым актам по правам человека 28.09.1990, были ратифицированы Международный Пакт о гражданских и политических правах от 16.12 .1966 (28.07.1990); Международный Пакт об экономических, социальных и культурных правах от 16.12.1966 (28.07.1990); Европейская Конвенция от 04.11.1950 о защите прав человека и основных свобод (24.07.1997), а также ряд других международных актов регламентирующих основные стандарты прав человека в отдельных областях, как права женщин, детей, беженцев, национальных меньшинств, расовых групп, включая большое количество конвенций Международной Организации Труда (МОТ). Однако, практика и уровень выполнения государством перечисленных норм, констатируется удручающими решениями ЕСПЧ против Республики Молдова, докладами ОБСЕ, Госдепа США и многими другими. Совокупность изложенного указывает, что в капиталистическом, демократическом, правовом государстве, сторона де-юре, существенно отличается от стороны де-факто.
В этом смысле, наилучшим примером по упразднению эффективности института власти народа и обессиливания провозглашаемых западной демократией ценностей прав и свобод человека, служит провидение одного из самых почитаемых президентов США Авраама Линкольна 1809-1865, который незадолго до своей гибели, высказал пророческие опасения о подавлении политической воли национальной власти диктатурой капитала: «В недалеком будущем наступит перелом, который крайне беспокоит меня и заставляет трепетать за судьбу моей страны... Приход к власти корпораций неизбежно повлечет за собой эру продажности и разложения в высших органах страны, и капитал будет стремиться утвердить свое владычество, играя на самых темных инстинктах масс, пока все национальные богатства не сосредоточатся в руках немногих избранных, — а тогда конец республике» [10].

Что вызывает особый интерес в исследовании этой области, так это то, что аналогичные выводы по обесправливанию граждан диктатурой капитала, при фактическом превозношении западных демократических ценностей прав и свобод человека, многосторонне, обоснованно и состоятельно охарактеризовал российский революционер, советский политический, государственный, военный и партийный деятель, генералиссимус, Генсек ЦК КПСС Иосиф Виссарионович Сталин $(1879$ - 1953). Выдержка из политического отчета Центрального Комитета о мировом кризисе, который 27 июня 1930 г. он делал XVI съезду ВКП(б): «Если бы капитализм мог приспособить производство не к получению максимума прибыли, а к систематическому улучшению материального положения народных масс, если бы он мог обращать прибыль не на удовлетворение прихотей паразитических классов, не на усовершенствование методов эксплуатации, не на вывоз капитала, а на систематический подъём материального 
положения рабочих и крестьян, то тогда не было бы кризисов. Но тогда и капитализм не был бы капитализмом. Чтобы уничтожить кризисы надо уничтожить капитализм» [11].

\section{Выводы}

Накладывая изложенную формулу на современные обстоятельства Республики Молдова, при которых значительная часть экономики находится под финансовой зависимостью западных партнеров, а те в свою очередь качественно не меняют область прав человека к лучшему, но регулярно инициируют и финансируют различные конференции на соответствующую тему, напрашивается логичный вывод, что конституционные гарантии прав человека зависят как от политической воли власти, так и от уровня экономики государства, при соизмерении его интересов с оказывающими материальную помощь внешними партнерами. Иными словами, политическая воля национального уровня не обладает суверенитетом, независимостью и абсолютной властью над полнотой эффективного исполнения конституционных гарантий прав человека. А наоборот, находится в зависимости от купы субъективных интересов народных делегатов, при взаимодействии с экономическими возможностями государства и диктатурой капитала внешних партнеров.

\section{Библиография}

1. Конституция РМ от 1994 [1], [8].

2. http://www.kant.narod.ru/leviath.htm [2].
3. https://proza.ru/2012/12/02/2025 [3].

4. НОБЕЛЬ, А., цитатник [4].

5. Победоносцев К.П. 1827 - 1907 [5].

6. ГЕББЕЛЬС, Й., цитатник 17 января 1930 года [6].

7. БЕРЕЗОВСКИЙ, Б., цитатник [7].

8. ДАННИНГ, Т., Дж., https://ru.wikipedia. org/wiki/цитата [9].

9. ФИЛИП, П., https://www.kp.md/daily/ 26549/3565772/ [10].

10. ЛИНКОЛЬН, Ав. 1809 - 1865 https:// ru.citaty.net/temy/kapital/ [11].

11. СТАЛИН, И.В. Сочинения, Том 12 , Госполитиздат, 1949 г. стр. 235-373 [12].

12. МИШИН, А.А., БАРЕНБОЙМ, П.Д. Адвокатура Нью-Йорка и правящая элита США // Вестн. Моск. ун-та: Право. 1985. № 3.

13. ИЛЬИНСКИЙ, И.П., МИШИН, А.А., ЭНТИН ,Л.М. Политическая система современного капитализма. М.: Международные отношения, 1983.

14. МИШИН, А.А., Буржуазная демократия и современная идеологическая борьба. М.: Знание, 1972.

15. МИШИН, А.А., Центральные органы власти буржуазных государств. М.: МГУ, 1972.

16. МИШИН, А.А., Конституционное (государственное) право зарубежных стран. 10-е изд., перераб. и дополн. М.: Юридический Дом «Юстицинформ», 2003.

17. ИВАНОВ, В.М., «Конституционное право Республики Молдова» Кишинев 2000г.

18. ФЕДОРОВ, Г.К., «Теория государства и права» Кишинев 1998г.

19. Декларация о независимости Республики Молдова от 27.08.1991г.

20. Всеобщая декларация прав человека, принятая Генеральной Ассамблеей $\mathrm{OOH}$

21. Всеобщая декларация прав человека 1948 .

22. Международный пакт о гражданских и политических правах 1966 г. 